\title{
Knowledge and Practices on Breast Cancer among Bangladeshi Female University Students: A Cross-sectional Study
}

\author{
Md. Sabbir Ahmed ${ }^{1}$, Abu Sayeed ${ }^{2}$, Trisha Mallick ${ }^{3}$, H M Syfuddin ${ }^{4,5}$
}

${ }^{1}$ Department of Community Health and Hygiene, Patuakhali Science and Technology University, Dumki, Patuakhali-8602, Bangladesh. ${ }^{2}$ Department of Post-harvest Technology and Marketing, Patuakhali Science and Technology University, Dumki, Patuakhali-8602, Bangladesh. ${ }^{3}$ Faculty of Nutrition and Food Science, Patuakhali Science and Technology University, Dumki, Patuakhali-8602, Bangladesh. ${ }^{4}$ Department of Biochemistry \& Molecular Biology, Shahjalal University of Science \& Technology, Sylhet-3114, Bangladesh. ${ }^{5}$ Department of Oncology, Old Road Campus Research Building (ORCRB), Roosevelt Drive, University of Oxford, Oxford, OX3 7DQ, United Kingdom.

\begin{abstract}
Objective: Breast cancer (BC) is the leading and most prevalent form of cancer among women in Bangladesh and worldwide. The objectives of this study were to assess the existing knowledge on breast cancer and the practices of breast self-examination among female Bangladeshi university students. Method: A cross-sectional study was carried out among the 276 female university students. Data were collected by face-to-face interview by using a pre-tested questionnaire. Results: The study results indicate that most of the participants were well informed about breast cancer. Predominantly mentioned signs of breast cancer was a lump in the breast followed by pain in the breast or nipple. The correct responses of breast cancer risk factors were exposure to radiation $(58.20 \%)$, positive family history $(47.6 \%)$, obesity $(46.9 \%)$, lack of physical exercise $(43.6 \%)$ and smoking $(43.2 \%)$. The students were well informed about breast self-examination for early diagnosis, but they were not properly informed about frequency. Only $17 \%$ reported that they practiced breast self-examination. Respondent's age, religion, marital status, having a problem in Breast and practices of breast self-examinations were significantly associated $(\mathrm{p}<0.05)$ with the knowledge scores in different aspects of breast cancer. Conclusion: The findings of this study indicate that the female students had inadequate knowledge on different aspects of $\mathrm{BC}$ and low compliance to recommended BSE practices. Initiating BC educational programs among university students is highly recommended for the early detection and treatment of this increasingly alarming disease.
\end{abstract}

Keywords: Breast cancer knowledge- Breast self-examination- female students- Bangladesh

\section{Introduction}

Globally, Breast cancer (BC) is one of the most common types of cancer among females which poses a global public health concern [1] and the second leading cause of cancer deaths among the females in Bangladesh (16.9\%) [2]. Globally more than 1 million new cases of $\mathrm{BC}$ are diagnosed every year, and the incidence rate is increasing rapidly both developed and developing countries [3]. It is also reported that more than half $(60 \%)$ of the $\mathrm{BC}$ deaths occur in economically developing countries [4].

Bangladesh is still lacking a National Cancer Registry [5]. So far no exertion has been made toward making population-based cancer registries or a central cancer registry to supply comprehensive across the country information. Therefore, the incidence and prevalence rate of breast cancer is mostly unknown in Bangladesh [6]. Though the causes of $\mathrm{BC}$ are not fully known, different studies have shown that risk for $\mathrm{BC}$ is due to a combination of some factors, among them some are modifiable and some are non-modifiable [7-8]. Some of the risk factors for $\mathrm{BC}$ are; Older age, early menarche, late menopause, physically inactive, overweight or obesity, having dense breasts, use of different hormone therapy, oral contraceptives, exposure to radiation, genetic

\section{Corresponding Author:}

Md. Sabbir Ahmed

Department of Community Health and Hygiene, Patuakhali Science and Technology University, Dumki, Patuakhali-8602, Bangladesh.

Email: sabbir.nfs@gmail.com 
mutation, alcohol consumption etc. [8-9].

Even though breast cancer is a leading cause of cancer death among Bangladeshi women, numerous women are totally uninformed of their ailment since social disgrace connected to sexual organs [10]. Adequate knowledge and awareness about the signs and symptoms and early breast cancer detection through breast self-examination (BSE) or clinical breast examination (CBE) or mammogram, is crucial to reducing breast cancer-related morbidity and mortality [9-11-12]. Unfortunately, only a few women practice those methods to examine their breasts [13]. Though only BSE is not an effective tool to early detection of $\mathrm{BC}$ but it is simple, non-invasive, convenient, inexpensive and available to all women, which helps the woman in early detection of any abnormal lump or mass in her breast [12] but, a percentages of women don't even know how to perform BSE [13-14].

Several cross-sectional studies on Knowledge, Attitude and Practice (KAP) of BC have been conducted among the Bangladeshi women [15-16], female university students in Jordan [12], Uganda [4], Yemen [13], Saudi Arabia [17-18] and health workers in Turkey [19]. However, very little is known about knowledge, attitudes, and practice regarding $\mathrm{BC}$ and $\mathrm{BSE}$ among Bangladeshi female university students. Only one study was found where the researcher investigated the knowledge level and practices regarding only BSE [20]. To the best of our knowledge, no studies were found regarding knowledge level on different aspects of $\mathrm{BC}$ e.g. etiology and prognosis, risk factors, signs of BC, practices of BSE etc. in Bangladesh. Therefore, the objectives of this study were to 1) assess the existing knowledge on different aspects of BC among the female university students; 2) evaluate the practices of BSE among the students and 3) assess the difference of the knowledge scores among the female university students based on their socio-demographic characteristics. This study is important in providing information on knowledge and BSE practice among female university students in Bangladesh. This study may be useful to the governmental and non-governmental organizations in the design of interventions aimed at effective prevention of breast cancer at the national level.

\section{Materials and Methods}

\section{Study design and setting}

This descriptive cross-sectional study was carried out among the female university students of Patuakhali Science and Technology University, Bangladesh from March to April 2019. It is the first and largest public university in the southern region of Bangladesh.

\section{Sample size and sampling technique}

Considering the total number of female students enrolled in this university (1200), Margin of error (5\%), Confidence Interval (95\%), a sample size of 292 participants was calculated. Hoping to get a response rate of $90 \%$, and adding $10 \%$ for non-response, resulting in a sample of 320 female students. The major selection criteria of the participants were a regular student of the university and willing to participate in the survey. There was no age restriction during the selection process. Students who refused to take part in the study, or did not complete the questionnaire were excluded from the study.

Being fully residential university all students live in the university dormitory. Hall attach number which was obtained from the provost office of two female dormitories in the university was used as a sampling frame. Simple random sampling technique was used to select the study participants from the sampling frame.

\section{Data collection tools and technique}

A self-administered pre-tested questionnaire was used to collect data from the respondents. The questionnaire includes three sections. The first section contained socio-demographic information of the respondents including age, marital status, level of study, faculty, permanent residential status, family history of BC etc. The second section was used to assess participants' knowledge of BC using $28 \mathrm{Yes} / \mathrm{No} / \mathrm{Don}$ 't know items divided into four aspects; including $\mathrm{BC}$ etiology and prognosis (6 items), $\mathrm{BC}$ risk factors (10 items); BC signs ( 7 items), and BSE (5 items). The assessment was done by scoring breast cancer knowledge computed by giving " 1 " to the correct answer, and " 0 " for the wrong and 'do not know' answers. Furthermore, total obtain marks were calculated separately for each of the aspects of BC for each of the students. Then it was converted into percentages to assess the knowledge scores. This section was obtained from previous published studies in India and Eritrea [9-21]. The last section of the questionnaire was used to assess the participant's practices of BSE and it was obtained and modified from previously published papers in Uganda and Nigeria [4-22].

\section{Ethical consideration}

Ethical approval for this study was obtained from the Institutional Ethical Committee (IEC) of Patuakhali Science and Technology University (Ref. No. PSTU/ IEC/2019/02). Written informed consent and was obtained from each of the participants, containing the contact address of the researcher for possible communication. The purpose, the process, and the confidentiality of the data was described in the consent form. They were informed that there will be no financial or other incentives for participating in the study and that their participation is voluntary. They were also told that they may withdraw the participation in the study at any time after initial participation, without any prejudice or penalty.

\section{Data analysis}

Descriptive statistics were used to describe demographic and main study variables. Results were expressed in frequency and percentage for categorical variables while quantitative variables were reported as mean and standard deviation. Bivariate analysis was done using independent sample t-test (for binary variables) and ANOVA (for more than two variables) to assess the difference between knowledge scores on different aspects of $\mathrm{BC}$ based on participant's socio-demographic characteristics. $\mathrm{p}<0.05$ was considered statistically significant. All the data were 
analyzed using IBM SPSS (version 23) and Microsoft word (2013) was used to tabular representation of data.

\section{Results}

A total of 276 female university students participated in the study with the mean age of $20.93( \pm 1.73)$. More than thee fourth of the participants were Muslim (76.8\%). The majority of the participants were unmarried (92.4\%). Most of them were an undergraduate students and studied

Table 1. Socio-demographic Characteristics of the Respondents $(\mathrm{n}=276)$

\begin{tabular}{|c|c|c|}
\hline Variables & Frequency & Percentage \\
\hline \multicolumn{3}{|l|}{ Age (years) } \\
\hline$\leq 21$ & 166 & 60.1 \\
\hline$\geq 22$ & 110 & 39.9 \\
\hline Mean $\pm \mathrm{SD}(\min -\max )$ & $20.93 \pm 1.73(18-25)$ & \\
\hline \multicolumn{3}{|l|}{ Age at menarche } \\
\hline Mean \pm SD (min-max) & $12.51 \pm 0.96(10-14)$ & \\
\hline \multicolumn{3}{|l|}{ Religion } \\
\hline Muslim & 212 & 76.8 \\
\hline Hindu & 64 & 23.2 \\
\hline \multicolumn{3}{|l|}{ Marital status } \\
\hline Unmarried & 255 & 92.4 \\
\hline Married & 21 & 7.6 \\
\hline \multicolumn{3}{|l|}{ Level of study } \\
\hline Undergraduate & 242 & 87.7 \\
\hline Graduate & 34 & 12.3 \\
\hline \multicolumn{3}{|l|}{ Faculty } \\
\hline Biological science & 210 & 76.1 \\
\hline Engineering & 26 & 9.4 \\
\hline Business studies & 40 & 14.5 \\
\hline \multicolumn{3}{|l|}{ Permanent residence } \\
\hline Rural area & 107 & 38.8 \\
\hline Urban area & 169 & 61.2 \\
\hline \multicolumn{3}{|l|}{ Monthly expenditure } \\
\hline$<5000 \mathrm{BDT}$ & 239 & 86.6 \\
\hline$\geq 5000 \mathrm{BDT}$ & 37 & 13.4 \\
\hline \multicolumn{3}{|c|}{ Family history of breast cancer } \\
\hline Absent & 218 & 79.0 \\
\hline Present & 14 & 5.1 \\
\hline Don't know & 44 & 15.9 \\
\hline \multicolumn{3}{|c|}{ Know about a breast cancer patient } \\
\hline No & 212 & 76.8 \\
\hline Yes & 64 & 23.2 \\
\hline \multicolumn{3}{|l|}{ Have any breast problem } \\
\hline Yes & 11 & 4.0 \\
\hline No & 265 & 96.0 \\
\hline \multicolumn{3}{|c|}{ Attend any workshop or seminar on breast cancer } \\
\hline Yes & 20 & 7.2 \\
\hline No & 256 & 92.8 \\
\hline \multicolumn{3}{|l|}{ Total knowledge score $(0-28)$} \\
\hline Mean $\pm \mathrm{SD}(\min -\max )$ & $12.35 \pm 4.83(4-26)$ & \\
\hline
\end{tabular}

Table 2. Knowledge on Breast Cancer among the Female University Students $(n=276)$

\begin{tabular}{|c|c|}
\hline Knowledge on different aspect of breast cancer & $\begin{array}{l}\text { Correct response } \\
\mathrm{N}(\%)\end{array}$ \\
\hline \multicolumn{2}{|l|}{ Breast Cancer etiology and prognosis } \\
\hline i. It is the most common cancer in women & $224(82.1)$ \\
\hline ii. It occurs more in old age & $59(21.6)$ \\
\hline iii. It can be inherited & $101(37.0)$ \\
\hline iv. It can present as painless breast lump & $158(57.9)$ \\
\hline v. Early diagnosis improves treatment outcome & $167(61.2)$ \\
\hline vi. It may be curable with early detection & $172(63.0)$ \\
\hline \multicolumn{2}{|l|}{ Risk Factors of Breast Cancer } \\
\hline i. Positive family history & $130(47.6)$ \\
\hline ii. Unmarried or without children & $64(23.4)$ \\
\hline iii. Old age & $48(17.6)$ \\
\hline iv. Early menarche & $40(14.7)$ \\
\hline v. Late menopause & $74(27.1)$ \\
\hline vi. Consumption of fatty food & $95(34.8)$ \\
\hline vii. Lack of physical exercise & $119(43.6)$ \\
\hline viii. Smoking & $118(43.2)$ \\
\hline ix. Obesity & $128(46.9)$ \\
\hline $\mathrm{x}$. Exposure to radiation & $159(58.20$ \\
\hline \multicolumn{2}{|l|}{ Signs of breast cancer } \\
\hline i. Inverted nipples & $103(37.5)$ \\
\hline ii. Swelling or a lump in the armpit & $105(38.2)$ \\
\hline iii.Dissimilarity in size of breast or nipple & $149(54.2)$ \\
\hline iv. Pain in the breast or nipple & $160(58.2)$ \\
\hline v. Discharge from the breast or nipple & $115(41.8)$ \\
\hline vi. A change in the skin texture such as dimpling & $104(37.8)$ \\
\hline vii. Lump in the breast & $235(85.5)$ \\
\hline \multicolumn{2}{|l|}{ Breast Self-Examination (BSE) } \\
\hline i. It helps in early diagnosis & $221(82.8)$ \\
\hline ii. It is recommended to be done monthly & $73(27.3)$ \\
\hline $\begin{array}{l}\text { iii. Suitable time to do BSE is } 7 \text { days after the } \\
\text { start of menstruation }\end{array}$ & $65(24.3)$ \\
\hline iv. It is done in front of mirror & $83(31.1)$ \\
\hline $\begin{array}{l}\text { v. Palm of the hand should be used while doing } \\
\text { BSE }\end{array}$ & $113(42.3)$ \\
\hline
\end{tabular}

in biological science faculty. More than half of the participants came from an urban area $(61.2 \%)$. Most of the participants had no personal history of a breast problem and they did not attend any seminar on breast cancer $(96 \%$ and $92.8 \%$ respectively) (Table 1 ).

Knowledge on different aspects of breast cancer is summarized in Table 2. Breast cancer was reported as the most common cancer among women $(82.1 \%)$ by the participants. It was observed that $61.2 \%$ of participants believed that early diagnosis of breast cancer improved treatment outcomes. Only $21.6 \%$ (59) knew that it occurs in old age. Table 2 also shows that lump in the breast was the predominantly mentioned signs of breast cancer followed by pain in the breast or nipple. More than half of the respondents $(54.2 \%)$ stated that dissimilarity in the size of a breast or nipple is the major sign of breast. Besides that, about $41.8 \%$ of the respondents stated that discharge from the breast or nipple, swelling or a lump 
Table 3. Participants Source of Knowledge about Breast Cancer $(\mathrm{n}=276)$

\begin{tabular}{lcc}
\hline Source & Frequency* & Percentage \\
\hline Friends & 52 & 18.8 \\
Family member & 65 & 23.6 \\
Doctor & 11 & 4.0 \\
News paper & 37 & 13.4 \\
Television & 37 & 13.4 \\
Internet & 54 & 19.6 \\
Social campaign & 14 & 5.1 \\
Others** & 6 & 2.2 \\
\hline
\end{tabular}

*Responses were mutually exclusive; **Others includes; book, magazine and seminar.

in the armpit (38.2\%), change in the size of the breast $(54.2 \%)$ and discoloration/ dimpling of the breasts (37.8\%) are the major signs of breast cancer. Inverted nipples were the least $(37.5 \%)$ mentioned the sign and symptoms of breast cancer. The correct responses of breast cancer risk factors were exposure to radiation $(58.20 \%)$, positive family history $(47.6 \%)$, obesity $(46.9 \%)$, lack of physical exercise $(43.6 \%)$ and smoking $(43.2 \%)$. The students were well informed about breast self-examination for early diagnosis but they were not properly informed about frequency (examine monthly). However, 42.3\% of students knew the use of the palm of the hand during breast self-examination.

Most of the participants became acquainted shown the knowledge of breast cancer from a family member $(23.6 \%)$ followed by the internet $(19.6 \%)$. Nearly one-fifth of the participant's source of knowledge about breast cancer was friends (18.8\%) (Table 3).

Next, we assessed the actual situation of breast self-examination practice. More than half of the participants did not hear about BSE (53.4\%) and $83 \%$ of the participant did not practice BSE. Among the positive responder for BSE practice, $62.2 \%$ did it once a month. Among the negative responder for BSE practice, 25.1\% think they don't have any breast problem and $16.5 \%$ don't do it for her carelessness. About $27.3 \%$ of the negative responder was planning to perform BSE (Table 4).

Table 5 shows the associations between knowledge scores of breast cancer and socio-demographic characteristics. The average mean score is higher in most cases among the students aged $\geq 22$ years. In this study, age and religion of the student were associated with student knowledge. In addition faculty and permanent residence of the student were not associated with student knowledge on breast cancer. However, there was the highest significant association between BSE knowledge and BSE practice $(p<0.001)$. Level of the study and having breast problem was significantly associated with knowledge on BSE and knowledge on $\mathrm{BC}$ sign respectively $(\mathrm{p}<0.05)$.

\section{Discussion}

The results of the study disclosed the knowledge of breast cancer including risk factors and breast self-examination of university female student leading towards early detection of breast cancer and increase chances of survival. In the current study, $58.2 \%$ of the student agreed that breast cancer may present as pain in the breast or nipple. This was similar to the findings from one study in Saudi Arabia [18] and higher than a similar study in the same country [23]. Only $1.75 \%$ accepted that nipple discharge might be a symptom of breast cancer and $23 \%$ participants agreed that it may present as a breast lump in a study of Saudi Arabia [23], which is much lower than another study $(65.3 \%$ \& $55.3 \%$ respectively) in Saudi Arabia [18], as well as the current study $(41.8 \%$ \& $85.5 \%)$. In the present study, the knowledge about the risk factor of breast cancer was significantly lower than the study of Rabia but significantly higher than Alam,s Study. As for example Alam finds that only $39.1 \%$ of the participant knew that heredity is a factor of breast cancer, $13.8 \%$ agreed that risk of breast cancer increases with advancing age, $15.95 \%$ knew that regular exercise may reduce the risk [24], in contrast to the proportion of participants in our study which is $47.6 \%, 17.6 \%, 43.6 \%$ respectively and was $77.3 \%, 93.3 \%, 62.7 \%$ respectively in the study of Rabia [18]. Among the risk factors with sufficient evidence,

Table 4. Student's Practices of Breast Self-examination (BSE)

\begin{tabular}{lcc}
\hline variables & Frequency & Percentage \\
\hline Heard about breast self-examination & & \\
$\quad$ Yes & 129 & 46.7 \\
No & 147 & 53.4 \\
Practice breast self-examination & & \\
Yes & 45 & 16.3 \\
No & 231 & 83.7
\end{tabular}

Frequency of practice of breast self-examination $(n=45)$

Once a week

$5 \quad 11.1$

Once a month

28

62.2

Once a year

12

26.7

Reasons for not practicing breast self-examination $(n=231)$

$\begin{array}{lcc}\text { I don't have breast problem } & 58 & 25.1 \\ \text { I don't think I should } & 14 & 6.1 \\ \text { I just don't feel like doing it } & 32 & 13.9 \\ \text { I leave it for doctors and } & 6 & 2.6 \\ \text { nurses to do } & & \\ \text { Carelessness } & 38 & 16.5 \\ \text { Laziness } & 32 & 13.9 \\ \text { I don't know } & 51 & 22.1\end{array}$

Planning to perform breast self-examination $(n=231)$

$\begin{array}{lcc}\text { Yes, in the next month } & 42 & 18.2 \\ \text { Yes, not in the next month } & 21 & 9.1 \\ \text { No } & 49 & 21.2 \\ \text { I don't know } & 119 & 51.5\end{array}$


Table 5. Bivariate Analysis of Factors Associated with Knowledge Scores on Different Aspect of Breast Cancer

\begin{tabular}{|c|c|c|c|c|c|c|}
\hline & $\mathrm{N}$ & $\begin{array}{l}\text { Knowledge on etiology } \\
\text { and Prognosis } \\
\text { Mean }( \pm \text { SD) }\end{array}$ & $\begin{array}{c}\text { Knowledge on risk } \\
\text { factors } \\
\text { Mean }( \pm \mathrm{SD})\end{array}$ & $\begin{array}{c}\text { Knowledge on BC } \\
\text { signs } \\
\text { Mean }( \pm \mathrm{SD})\end{array}$ & $\begin{array}{l}\text { Knowledge on aspect of } \\
\text { breast self-examination } \\
\text { Mean }( \pm \text { SD })\end{array}$ & $\begin{array}{c}\text { Total knowledge } \\
\text { score } \\
\text { Mean }( \pm \mathrm{SD})\end{array}$ \\
\hline \multicolumn{7}{|l|}{ Age } \\
\hline$\leq 21$ & 166 & $51.81 \pm 24.20$ & $34.16 \pm 19.23$ & $50.52 \pm 24.99$ & $37.95 \pm 23.67$ & $42.71 \pm 17.64$ \\
\hline$\geq 22$ & 110 & $55.30 \pm 21.52$ & $37.09 \pm 18.29$ & $50.26 \pm 22.79$ & $48.00 \pm 32.30$ & $46.23 \pm 16.51$ \\
\hline$P$ value & & 0.221 & 0.207 & 0.931 & $0.003 * *$ & 0.097 \\
\hline \multicolumn{7}{|l|}{ Religion } \\
\hline Muslim & 212 & $53.07 \pm 23.73$ & $36.13 \pm 19.37$ & $52.09 \pm 23.97$ & $43.77 \pm 28.96$ & $45.11 \pm 17.34$ \\
\hline Hindu & 64 & $53.65 \pm 21.51$ & $32.66 \pm 17.01$ & $44.87 \pm 23.85$ & $35.94 \pm 22.86$ & $40.79 \pm 16.64$ \\
\hline $\mathrm{p}$ value & & 0.861 & 0.197 & $0.035^{*}$ & $0.048^{*}$ & 0.079 \\
\hline \multicolumn{7}{|l|}{ Marital status } \\
\hline Unmarried & 255 & $53.20 \pm 23.74$ & $34.51 \pm 18.85$ & $50.31 \pm 24.54$ & $41.88 \pm 28.16$ & $43.78 \pm 17.58$ \\
\hline Married & 21 & $53.17 \pm 15.47$ & $45.24 \pm 16.61$ & $51.70 \pm 18.33$ & $42.86 \pm 23.90$ & $48.13 \pm 12.30$ \\
\hline $\mathrm{p}$ value & & 0.996 & $0.012^{*}$ & 0.800 & 0.878 & 0.268 \\
\hline \multicolumn{7}{|l|}{ Level of study } \\
\hline Undergraduate & 242 & $52.96 \pm 24.08$ & $35.04 \pm 18.78$ & $50.83 \pm 24.75$ & $40.58 \pm 25.27$ & $43.82 \pm 17.42$ \\
\hline Graduate & 34 & $54.90 \pm 15.64$ & $37.35 \pm 19.74$ & $47.48 \pm 18.84$ & $51.76 \pm 40.93$ & $46.22 \pm 16.11$ \\
\hline $\mathrm{p}$ value & & 0.649 & 0.505 & 0.449 & $0.028^{*}$ & 0.448 \\
\hline \multicolumn{7}{|l|}{ Faculty } \\
\hline Biological science & 210 & $52.94 \pm 22.95$ & $35.90 \pm 19.37$ & $49.39 \pm 22.59$ & $42.38 \pm 29.21$ & $44.08 \pm 17.41$ \\
\hline Engineering & 26 & $51.92 \pm 22.76$ & $31.15 \pm 17.04$ & $57.14 \pm 26.49$ & $41.54 \pm 19.53$ & $43.96 \pm 15.54$ \\
\hline Business studies & 40 & $55.42 \pm 25.14$ & $35.00 \pm 17.39$ & $51.43 \pm 25.01$ & $40.00 \pm 25.21$ & $44.38 \pm 17.88$ \\
\hline $\mathrm{p}$ value & & 0.791 & 0.479 & 0.291 & 0.882 & 0.994 \\
\hline \multicolumn{7}{|l|}{ Permanent residence } \\
\hline Rural area & 107 & $51.87 \pm 22.11$ & $35.79 \pm 17.32$ & $48.73 \pm 21.75$ & $41.50 \pm 24.67$ & $43.49 \pm 16.05$ \\
\hline Urban area & 169 & $54.04 \pm 23.88$ & $35.03 \pm 19.85$ & $51.48 \pm 25.48$ & $42.25 \pm 29.71$ & $44.51 \pm 18.01$ \\
\hline $\mathrm{p}$ value & & 0.449 & 0.744 & 0.357 & 0.827 & 0.635 \\
\hline \multicolumn{7}{|c|}{ Have any breast problem } \\
\hline Yes & 11 & $53.03 \pm 28.69$ & $29.09 \pm 18.68$ & $64.94 \pm 30.21$ & $43.64 \pm 17.47$ & $45.78 \pm 19.15$ \\
\hline No & 265 & $53.21 \pm 23.01$ & $35.58 \pm 18.88$ & $49.81 \pm 22.69$ & $41.89 \pm 28.19$ & $44.04 \pm 17.21$ \\
\hline $\mathrm{p}$ value & & 0.980 & 0.265 & $0.041^{*}$ & 0.839 & 0.744 \\
\hline \multicolumn{7}{|l|}{ Practice BSE } \\
\hline Yes & 45 & $58.52 \pm 24.26$ & $38.44 \pm 21.20$ & $53.02 \pm 28.18$ & $55.11 \pm 32.23$ & $49.37 \pm 20.35$ \\
\hline No & 231 & $52.16 \pm 22.89$ & $34.72 \pm 18.38$ & $49.91 \pm 23.26$ & $39.39 \pm 26.20$ & $43.09 \pm 16.44$ \\
\hline $\mathrm{p}$ value & & 0.093 & 0.227 & 0.490 & $0.000 * * *$ & 0.056 \\
\hline
\end{tabular}

Significant at $\mathrm{p}<0.05, * *$ Significant at $\mathrm{p}<0.01, * * *$ Significant at $\mathrm{p}<0.001$

nearly half $(47.6 \%)$ of the participants in the current study accurately marked that positive family history increased the risk of developing breast cancer in female students. In a study conducted among urban women in Ahmedabad city revealed $27.6 \%$ of their participants were aware that family history increases breast cancer risk [25]. However, another study reported $60 \%$ of women were aware of the importance of familial history [21], while a study among South Indian women reported only $13 \%$ of women with this knowledge [26]. In the study, $63 \%$ of participant believed that breast cancer is curable with early detection which is lower $(68 \%)$ than the study done by Neha [21] but higher (41.4\%) than Michael's study [22]. In a study in Delhi, $76 \%$ responder thought BSE helps in early diagnosis [21] which is lower than our study (82.8\%) but in Nigeria, the result was higher $(87.2 \%)$ than our result [22]. Our results indicate that only $16.3 \%$ of our participants perform BSE regularly with frequency ranging from once a month in $62.2 \%$ subjects to once a year in $26.7 \%$. Where the practice rate was $49.1 \%$ and $34.9 \%$ in the participant of Delhi [21] and Nigeria [22] (respectively). Another study done by Choudhary revealed that only $12 \%$ of the participants practiced BSE monthly [27]. However, the practice of BSE among nurses is higher in some studies than in the present study [28-30]. The results of our study suggest that a higher age group $(\geq 22)$ had been associated with their knowledge on the aspect of breast self-examination where a study in Delhi among the age group less than 30 was associated too [21]. In the present study, the knowledge on aspect of breast self-examination was significantly lower in student who had lower educational status (undergraduate student) ( $\mathrm{p} \leq 0.05$ ), we found the same evidence from multiple Indian studies which found relatively higher knowledge 
on breast self-examination among populations with higher educational attainments like urban women, school teachers and nurses [31-32]. Our results indicate that the history of breast cancer in a family significantly influenced the knowledge of signs of breast cancer. In addition, a study done by Neha was also significant with knowledge of signs of BC and family history [21]. Knowledge on BSE was significant at $p<0.001$ with the practice of BSE. The high difference between knowledge of BSE and actual practice by the participant shows that acceptability of BSE is still low with almost four-fifths of the participants in the current study have never been practicing it.

In conclusion, this was the first study to assess the KAP of female Bangladeshi university students about breast cancer. The findings of this study indicate that the female students had inadequate knowledge on different aspects of $\mathrm{BC}$ and low compliance to recommended BSE practices. Such research findings point out the significance of raising student's awareness with respect to $\mathrm{BC}$ and practices of BSE for early detection of this increasing alarming disease. It is necessary to establish an institutional framework and national policy guidelines to increase the adequate dissemination of information about the risk factors, sign-symptoms, importance of BSE practices and other recommended approaches to control the disease. It will be useful in the early detection and reporting of breast cancer for better treatment.

\section{Limitations}

Our present study is not without limitations. Firstly, it is limited by the self-reported data which might have influenced the results through respondent bias. The study is also limited by a relatively small sample size and recruiting sample from only one university, so generalization of the whole country was not possible. However, being the first study to investigate this topic among such target population groups in Bangladesh will open the door for further studies in such an important field. Country representative studies are recommended to overcome such limitations.

\section{Acknowledgments}

The authors would like to thank all the participants in this study for their voluntary participation. Authors also wish to acknowledge Umme Saida, Morium Tuz Marufa, Mohammad Raihan Tariq and Joyshree Mondol, faculty of Nutrition and Food Science, PSTU for their voluntary support during data collection. Finally, the authors would like to thank Safyet Khan from BRAC for his support during manuscript preparation.

\section{Authors Contribution}

MSA and TM conceptualize and wrote the first draft. MSA analyzed the data. MSA and AS reviewed the literature. AS and HMS reviewed the paper. All authors approved the final version of the manuscript. Statement Conflict of Interest

Authors have no conflict of interest to disclose.

\section{Source of funding}

The authors did not receive any external sources of funding for this study

\section{References}

1. World Health Organization. Breast cancer: prevention and control [Internet]. 2019 [cited 2019 May 19]. p. 1. Available from: https://www.who.int/cancer/detection/breastcancer/en/

2. WHO. World Health Organization - Cancer Country Profiles, 2014. World health Organization. 2014.

3. Ferlay J, Soerjomataram I, Dikshit R, Eser S, Mathers $\mathrm{C}$, Rebelo $\mathrm{M}$, et al. Cancer incidence and mortality worldwide: sources, methods and major patterns in GLOBOCAN 2012. International journal of cancer [Internet]. 2015;136(5):E359-86. Available from: http:// www.ncbi.nlm.nih.gov/pubmed/25220842.

4. Katende Godfrey, Tukamuhebwa Agatha Nankumbi and J. Breast Cancer Knowledge and Breast SelfExamination Practices Among Female University Students in Kampala, Uganda: A Descriptive Study. Oman Medical Journal, [Internet]. 2016;31(2):129-34. Available from: https:// www.ncbi.nlm.nih.gov/pmc/articles/PMC4861385/pdf/ OMJ-D-15-00113.pdf.

5. Ministry of Heath and Family Welfare. Draft Final of National Cancer Control Strategy and Plan of Action 2009-15 [Internet]. 2008. Available from: http://dghs.gov.bd/bn/licts_file/images/ Strategy/2009_NationalCancerControlStrategy2009-15.pdf.

6. M.S. H, S. F, H.E. K-K. Breast cancer in South Asia: A Bangladeshi perspective. Cancer Epidemiology [Internet]. 2014;38(5):465-70. Available from: http://www.embase. $\mathrm{com} / \mathrm{search} /$ results? subaction $=$ viewrecord $\&$ from $=\exp$ ort\&id=L600230455\%0Ahttp://dx.doi.org/10.1016/j. canep.2014.08.004

7. Ayed, Ahmad, Faeda Eqtait, Lubna Harazneh Imad, Imad Fashafsheh Sewar, Sewar Nazzal, Bian Talahmeh, Deena Hajar RA. Breast Self-Examination in Terms of Knowledge, Attitude, and Practice among Nursing Students of Arab American University/ Jenin. Journal of Education and Practice [Internet]. 2015;6(32):27-31. Available from: www.iiste.org

8. OMS. What are the risk factors for breast cancer? [Internet]. Http://Www.Cancer.Org/Cancer/Breastcancer/ Detailedguide/Breast-Cancer-Risk-Factors. 2016 [cited 2019 May 20]. p. Available from: https://www.cdc.gov/cancer/ breast/basic_info/risk_factors.htm

9. Andegiorgish AK, Kidane EA, Gebrezgi MT. Knowledge, attitude, and practice of breast Cancer among nurses in hospitals in Asmara, Eritrea. BMC Nursing. 2018;17(1):33.

10 Dhaka Tribune. Social taboo leading cause for unchecked breast cancer in Bangladesh. 2018 Oct 27; Available from: https:// www.dhakatribune.com/bangladesh/event/2018/10/27/ social-taboo-leading-cause-for-unchecked-breast-cancerin-bangladesh

11. Pignone MP, Gaynes BN, Rushton JL, Burchell CM, Orleans CT, Mulrow CD, et al. Screening for depression in adults: a summary of the evidence for the U.S. Preventive Services Task Force. Annals of internal medicine [Internet]. 2002;136(10):765-76. Available from: http://www.ncbi.nlm. nih.gov/pubmed/12020146

12. Alsaraireh A, Darawad MW. Breast cancer awareness, attitude and practices among female university students A descriptive study from Jordan Health Care for Women International Vol 39, No 5. Health care for women international. 2018;39(5):571-83.

13. Ahmed BA. Awareness and practice of breast cancer and 
breast-self examination among university students in Yemen. Asian Pacific journal of cancer prevention : APJCP [Internet]. 2010;11(1):101-5. Available from: http://www. ncbi.nlm.nih.gov/pubmed/20593937

14. Siahpush M, Singh GK. Sociodemographic variations in breast cancer screening behavior among Australian women: results from the 1995 National Health Survey. Preventive medicine [Internet]. 2002;35(2):174-80. Available from: http://www.ncbi.nlm.nih.gov/pubmed/12200103

15. Begum SA, Mahmud T, Rahman T, Zannat J, Khatun F, Nahar $\mathrm{K}$, et al. Knowledge, Attitude and Practice of Bangladeshi Women towards Breast Cancer: A Cross Sectional Study. Mymensingh medical journal: MMJ. 2019;28(1):96-104.

16. Rasu RS. Rianon NJ. Shahidullah SM. Faisel AJ. Selwyn B. Effect of educational level on knowledge and use of breast. Health Care for Women International. 2011;32(3):177-89.

17. Habib F, Salman S, Safwat M, Shalaby S, Salman S, Radiologist C. Awareness and Knowledge of Breast Cancer Among University Students in Al Madina Al Munawara Region. Middle East Journal of Cancer [Internet]. 2010;1(4):159-66. Available from: http://repository.taibahu. edu.sa/bitstream/handle/123456789/5729/Awareness and Knowledge of Breast Cancer Among University Students in Al Madina Al Munawara Region..pdf?sequence $=1$

18. Rabia Latif. Knowledge and attitude of Saudi female students towards breast cancer: A cross-sectional study. Journal of Taibah University Medical Sciences. 2014;9(4):328-34.

19. Soylar P, Özer A, Doğan Yüksekol Ö, Ulucan M. Knowledge, Attitude, and Practice Regarding Cancer Screening Tests Among Health Workers in a University Hospital in Turkey. Journal of Cancer Education. 2019;1-6.

20. S P, K P. Knowledge, attitude and practice of breast selfexamination amongfemale university students from 24 low, middle income and emerging economy countries. Asian Pac J Cancer Prev. 2004;15(20):8637-40.

21. Dahiya N, Basu S, Singh MC, Garg S, Kumar R, Kohli C. Knowledge and Practices Related to Screening for Breast Cancer among Women in Delhi, India. Asian Pacific journal of cancer prevention : APJCP. 2018;19(1):155-9.

22. M.N. O, C.H. B, F.E. O, U. O. Knowledge, attitude and practice of Nigerian women towards breast cancer: A cross-sectional study. World Journal of Surgical Oncology. 2006;4(1):11

23. Jahan S, Al-Saigul AM, Abdelgadir MH. Breast cancer. Knowledge, attitudes and practices of breast self examination among women in Qassim region of Saudi Arabia. Saudi Medical Journal. 2006;27(11):1737-41.

24. Alam AA. Knowledge of breast cancer and its risk and protective factors among women in Riyadh. Annals of Saudi medicine [Internet]. 2006;26(4):272-7. Available from: http://www.ncbi.nlm.nih.gov/pubmed/16883082\%0Ahttp:// www.pubmedcentral.nih.gov/articlerender. fcgi?artid=PMC6074496

25. Bala D V, Gameti H. An educational intervention study of breast self examination (BSE) in 250 women beneficiaries of urban health centers of west Zone of Ahmedabad. Healthline, Journal of Indian Association of Preventive and Social Medicine [Internet]. 2011;2(2):46-9. Available from: http:// www.iapsmgc.org/OA11V2I2.pdf

26. Kumar Sharma P, Ganguly E, Nagda D, Kamaraju T. Knowledge, attitude and preventive practices of South Indian women towards breast cancer. The Health Agenda [Internet]. 2013;1(1):16-22. Available from: http://citeseerx. ist.psu.edu/viewdoc/download?doi=10.1.1.708.1154\&rep= rep1\&type $=$ pdf

27. Choudhry UK, Srivastava R, Fitch MI. Breast cancer detection practices of south Asian women: knowledge, attitudes, and beliefs. In: Oncology nursing forum [Internet]. 1998. p. 1693-701. Available from: http://www.ncbi.nlm. nih.gov/pubmed/9826837

28. Fotedar V, Seam RK, Gupta MK, Gupta M, Vats S, Verma S. Knowledge of Risk Factors \& Early Detection Methods and Practices towards Breast Cancer among Nurses in Indira Gandhi Medical College, Shimla, Himachal Pradesh, India. Asian Pacific Journal of Cancer Prevention. 2013;14(1):117-20.

29. Yousuf SA, Al Amoudi SM, Nicolas W, Banjar HE, Salem SM. Do Saudi Nurses in Primary Health Care Centres have Breast Cancer Knowledge to Promote Breast Cancer Awareness? Asian Pacific Journal of Cancer Prevention. 2013;13(9):4459-64.

30. Alkhasawneh IM. Knowledge and Practice of Breast Cancer Screening Among Jordanian Nurses. In: Oncology Nursing Forum. 2007. p. 1211-7.

31. Khokhar A. Level of awareness regarding breast cancer and its screening amongst Indian teachers. Asian Pac J Cancer Prev [Internet]. 2009;10(2):247-50. Available from: http:// www.ncbi.nlm.nih.gov/pubmed/19537892

32. Oza JR, Prajapati JD, Ram R. A study on awareness toward the early detection of breast cancer on nursing staff in civil hospital, Ahmedabad, Gujarat, India. Healthline. 2011;2(1):34-7.

\section{(i) (8)}

This work is licensed under a Creative Commons AttributionNon Commercial 4.0 International License. 